\title{
Assessment of Total Phenolic Content and Antioxidant Activity Potential of Clementine Extract Obtained by Microwave Assisted Extraction Method
}

\author{
Hanane Azzouzi ${ }^{1,2 *}$, Loubna Elhajji ${ }^{1}$, Mouad Achchoub ${ }^{1,2}$, \\ Mohammed Benbati ${ }^{2}$, Kaoutar El-Fazazi ${ }^{2 *}$ and Souad Salmaoui ${ }^{1}$ \\ ${ }^{1}$ Laboratory of environmental engineering, faculty of science and technology, \\ Sultan Moulay Slimane University, Béni Mellal, Morocco. 23000. \\ ${ }^{2}$ Agro-food Technology and Quality Laboratory, Regional Center of Agricultural Research of Tadla, \\ National Institute of Agricultural Research (INRA), Avenue Ennasr, BP 415 Rabat Principale, \\ 10090 Rabat, Morocco. \\ http://dx.doi.org/10.13005/bbra/2959
}

(Received: 21 September 2021; accepted: 26 October 2021)

Citrus peels are known as rich source of bioactive compounds. Therefore, the establishment of an appropriate and innovative extraction method is a major interest to the food processing industry. The aim of this work is to assess the total phenolic content (TPC) and antioxidant activity (AA) of peels extracts prepared from five Moroccan clementine varieties. Extracts were prepared with microwave-assisted extraction (MAE) technique using acetone and methanol solvents. The evaluation of the antioxidant activity was performed by DPPH and ABTS- free radical scavenging. The extraction conditions had significant effects on total phenolic content (TPC) and antioxidant activity (AA). In fact, the highest TPC amount of clementine varieties $(730.850 \pm 0.004 \mathrm{mg}$ GAE$/ 100 \mathrm{~g} D$ D) was obtained with acetone solvent for the Sidi Aissa variety. Regarding antioxidant activity, results with DPPH method showed an important antiradical and antioxidant activities for Sidi Aissa variety with methanol solvent $(46.30 \pm 1.01 \%)$. However, ABTS method showed a good antioxidant activity for Ain Taoujdat with methanol solvent $(3.02 \mathrm{mg} / 100 \mathrm{~g} \mathrm{DM})$. This work provided to study the biochemical quality of Moroccan clementine extracts obtained by two microwave-assisted extraction processes in order to investigate further industrial potential uses in agro-food and pharmaceutical industries

Keywords: Antioxidant Activity; Clementine; Extraction; Microwave; Polyphenols; peel.

The citrus sector plays an important socioeconomic role in most producing countries around the world. According to the results of the general citrus count conducted by the ministry of agriculture in 2019, Morocco produced about 2.62 million tons of citrus of which 715.000 tons were intended for export, representing a value of more than 4 billion dirhams. The varietal profile of the national citrus orchard is composed of a diverse range of varieties, but remains dominated by 3 groups of varieties, namely, the group of clementines with $35 \%$, the Morocco late with $21 \%$ and Navels with $18 \%^{1}$ Since 2019 Morocco has experienced a crucial and unexpected rise in the production of clementine 
with an increase of $200 \%$, with also the problem of the sanitary crisis (coronavirus covid-19) and the precautionary measures that have prevented trade operations between countries which has caused an overproduction of territories products and especially clementine.

Citrus fruit processing in the food industries consist mainly on juices, citrus-based beverages and jams production, which generate significant by product waste $^{2}$. This later has traditionally been valued as molasses for animal feed ${ }^{3,4}$, fiber production (pectin), and fuel production $^{5,6,7}$. Recently, several studies have reported that citrus peels are considered as a rich source of bioactive compounds. Moreover this by product is known for their important antioxidant capabilities, which have potentially beneficial effect for human health. Citrus peels contain high concentration of phenolic compounds, vitamin C, fiber, and carotenoids $8,9,10,11$.

Several researchers were interested in the extracting process of phenolic compounds, in order to be used as natural antioxidant ${ }^{12}$. These potential applications of citrus peels bioactive metabolites in functional food, pharmaceuticals, and cosmetics, as well as other areas like chemistry and material design. However, these applications are only viable if the molecules are isolated while maintaining their activity.

Microwave assisted extraction (MAE) is the process by which microwave energy is used to heat solvents in contact with solid samples and to partition compounds of interest from the sample into the solvent. Recently, (MAE) has received a great attention as a potential alternative to conventional extraction methods, mainly due to considerable savings in processing time, solvent consumption and energy ${ }^{13}$. In fact, published research reported on pomegranate, mandarin and potatoes peels has showed the interest of polyphenols content associated to the antioxidant activity due to the decomposition of bioactive compounds ${ }^{14,15,16}$.

Therefore, the extraction processes used must be performed under soft conditions to prevent bioactive compounds losses and to minimize the extraction costs (energy, quantity of solvent...). A considerable number of papers were published on microwave assisted extraction as an innovative technique of phenolic extraction on several fruit peels $^{17,18,19,20,21}$.

However, to our knowledge no previews work has been reported on the phenolic compounds extraction from Moroccan clementine peels using microwave assisted extraction. Therefore, the aim of this study is to evaluate the phenolic content and antioxidant potential of five varieties of clementine extracts obtained by microwave assisted extraction using two type of organic solvent.

\section{MATERIEL AND METHODS}

\section{Plant material}

The plant material employed in our study is the peels of five varieties of clementine (Citrus clementina), namely Nour, Ain Taoujdat, Nova, Orogrande, and Sidi Aissa. They were harvested in the Beni Mellal-Khénifra region of Morocco during the month of January 2021.

The peel samples were washed, peeled and dried for 8 days in a temperature-controlled greenhouse $\left(45^{\circ} \mathrm{C}\right)$. They were ground with an electric grinder to obtain a fine, homogeneous powder with a particle size of less than $120 \mathrm{im}$. The powder was stored in vacuum bags hermetically sealed and protected from the light in a freezer at $-18^{\circ} \mathrm{C}$.

\section{Extraction method}

The analysis of phenolic compounds and antioxidant activity of clementine peels is based on conventional solvent extraction (CSE) intensified by using microwave.

Five grams of clementine peel powder are introduced into the extraction chamber with 50 $\mathrm{mL}$ of solvent (methanol/water $80 \%$ and acetone/ water $50 \%$ ). The microwave assisted extraction is performed at a temperature of $35^{\circ} \mathrm{C}$, a time of $180 \mathrm{~s}$ and a power of $180 \mathrm{~W}$ using (Samsung microwave MG23K3515AK) .The mixture was then filtered through a sieve and centrifuged (Sigma 2-16 Germany) twice at a speed of $4000 \times \mathrm{g}$ for $15 \mathrm{~min}$. The supernatant was stored at $4{ }^{\circ} \mathrm{C}^{22}$.

Total polyphenols content (TPC)

The total polyphenol content was performed by spectrophotometry using the FolinCiocalteu reagent which is described by (Singleton and al, 1988) ${ }^{23}$. Three hundred microliters of each extract was added, at $1.5 \mathrm{~mL}$ of the Folin- 
Ciocalteu (1/10) mixture. After 5 min of incubation in darkness, $1.2 \mathrm{~mL}$ of $7.5 \%$ sodium carbonate $\left(\mathrm{Na}_{2} \mathrm{CO}_{3}\right)$ solution was added to the previous mixture. The tubes were shaken using (Velp scientifica shaker) and incubated for $90 \mathrm{~min}$ in darkness at room temperature. The total polyphenol content was reported as milligram equivalents of Gallic acid per gram of dry matter.

\section{Evaluation of antioxidant activity (AA) ABTS test}

The ABTS test was used to assess antioxidant activity following ( Re and al, 1999) $)^{24}$. A solution of ABTS $(3.5 \mathrm{mmol} / \mathrm{L})$ was mixed with $1.42 \mathrm{mmol} / \mathrm{L}$ of potassium persulfate $\left(\mathrm{K}_{2} \mathrm{~S}_{2} \mathrm{O}_{8}\right)$. After the addition of $2.2 \mathrm{~mL}$ of the standard solution (ABTS $\bullet$ ) to $800 \mathrm{iL}$ of clementine peel extract, the absorbance was measured after $1 \mathrm{~min}$ of incubation $\left(\mathrm{A}_{0}\right)$ and after $30 \mathrm{~min}\left(\mathrm{~A}_{\mathrm{t}}\right)$ at room temperature, the absorbance reading was taken at $734 \mathrm{~nm}$. The inhibition percentage was calculated, between $\mathrm{A} 0$ as:

Inhibition percentage $(\%)=(\mathrm{A} 0-\mathrm{At}) / \mathrm{A} 0$

\section{DPPH test}

This method is based on the measurement of the capacity of antioxidants to trap the DPPH radical. The effect of each extract on DPPH is measured according to (Seung and al, 2004) ${ }^{25}$. One hundred microliter of different concentrations of each extract is added to $2 \mathrm{~mL}$ of freshly prepared methanolic solution of DPPH $(0.2 \mathrm{mg} / \mathrm{mL})$ incubated in darkness. Absorbance reading is performed at $517 \mathrm{~nm}$.

\section{Statistical analysis}

Statistical evaluation of the data was done with the IMB SPSS Statistics V21 software. All assays were performed in triplicate and results are expressed as (average \pm SD). These different tests were completed by a statistical study of variance
(ANOVA) according to ( $\mathrm{X}^{2}$ Test) with the statistical significance level was set at $\mathrm{P}<0.05$.

\section{RESULTS AND DISCUSSION}

\section{Total polyphenol content}

The phenolic content in the different clementine extract peels are shown in Figure 1.

According to Figure 1, it was note that the acetone extracts present the highest values amount to the five varieties (Sidi Aissa, Nova, Ain Taoujdat, Orogrande, Nour) respectively: $730.850 \pm 0.003 \mathrm{mg}$ GAE/100g DM; 417.120 $\pm 0.004 \mathrm{mg}$ GAE/100g DM; 680.720 $\pm 0.003 \mathrm{mg}$ GAE/100g DM; 560.220 $\pm 0.004 \mathrm{mg}$ GAE/100g DM and $540.400 \pm 0.002 \mathrm{mg} \mathrm{GAE} / 100 \mathrm{~g}$ DM. However, at an average of $350.100 \pm 0.001 \mathrm{mg}$ GAE $/ 100 \mathrm{~g}$ DM for Sidi Aissa variety, the methanol extracts contain very low polyphenolic concentrations

The (MAE) extraction of total polyphenols in dry pomegranate peel shows that (MAE) was a more efficient extraction method, which yielded $199.4 \mathrm{mg} \mathrm{GAE} / \mathrm{g}$, after 4 min of extraction comparatively to ultrasound assisted extraction ${ }^{26}$. During microwave-assisted extraction of pomegranate peel phenolics, the absorption of microwave energy in the extraction system promoted the thermal accumulation of the extraction solution resulting in the dissolution of phenolics into the solution until $4 \mathrm{~min}^{27}$.

These results are in agreement with those of many authors who revealed that mixed solvents are very effective in extracting polyphenols. According to (Mohammedi and Atiki, 2011) ${ }^{28}$ the use of mixed solvents results in high enrichment of extracts with polyphenols. The superiority of mixed solvents would be due to the higher solubility of phenolic compounds in extracts obtained by mixed solvents compared to those by pure solvents ${ }^{29}$.

Table 1. Geographical coordinates of clementine varieties

\begin{tabular}{llll}
\hline \multirow{2}{*}{ Varieties } & Origins & Geographical coordinates \\
& & Latitude & Longitude \\
\hline \multirow{2}{*}{ Nour } & Afourar experimental field & 32.26224469350921 & -6.526784325199115 \\
Ain Taoujdat & Organic agricultural field (Sidi Jaber) & 32.38289655415102 & -6.363658822498275 \\
Nova & Organic agricultural field (Sidi Jaber) & 32.38286484284495 & -6.362014628372146 \\
Orogrande & Organic agricultural field (Sidi Jaber) & 32.38215360062728 & -6.361877835712386 \\
Sidi Aissa & Afourar Experimental Field & 32.26159374278428 & -6.5267561620044585 \\
\hline
\end{tabular}


Microwave-assisted extraction is a technique that uses microwave energy to enhance the extraction process. This treatment causes a temperature rise and internal pressure in the plant cell walls, which accelerates cell rupture ${ }^{22}$, ${ }^{30}$. Heating causes weak hydrogen bonds to be disrupted during microwave treatment, which is assisted by the dipolar rotation of molecules. Inside the biomaterial, a significant amount of pressure builds up, affecting the physical properties of biological cells and improving the porosity of the biological matrix. This increases the extraction of total polyphenols by allowing the extraction solvent to penetrate deeper into the matrix ${ }^{31}$.

\section{Antioxidant activity}

\section{ABTS Test}

The antioxidant potential was determined by the ABTS test which is expressed as IC $50 \%$ (Concentration inhibiting 50\% of the radicals), as shown in Table 2.

According to results presented in Table 2, all the extracts have an antiradical power towards
ABTS. In fact, with acetone solvent, IC50 values of Sidi Aissa, Nova, Ain Taoujdat, Orograndé and Nour varieties were $0.600 \pm 0.001 \mathrm{mg} / 100 \mathrm{~g} \mathrm{DM}$, $0.800 \pm 0.002 \mathrm{mg} / 100 \mathrm{~g} \mathrm{DM}, 1.200 \pm 0.001 \mathrm{mg} / 100 \mathrm{~g}$ $\mathrm{DM}, 1.400 \pm 0.002 \mathrm{mg} / 100 \mathrm{~g}$ DM and $1.010 \pm 0.002$ $\mathrm{mg} / 100 \mathrm{~g} \mathrm{DM}$, respectively.

Regarding extraction with methanol solvent, the IC50 values of Sidi Aissa, Nova, Ain Taoujdat, Orograndé and Nour varieties were $1.800 \pm 0.003 \mathrm{mg} / 100 \mathrm{~g} \mathrm{DM}, 1.600 \pm 0.002 \mathrm{mg} / 100 \mathrm{~g}$ $\mathrm{DM}, 3.020 \pm 0.002 \mathrm{mg} / 100 \mathrm{~g} \mathrm{DM}, 2.800 \pm 0.001$ $\mathrm{mg} / 100 \mathrm{~g}$ DM and $1.800 \pm 0.002 \mathrm{mg} / 100 \mathrm{~g} \mathrm{DM}$, respectively. By analyzing the results values, we can note that IC50 extracts values obtained with methanol solvent were significantly higher than those of acetone solvent $(\mathrm{P}<0.03)$.

The abilities of natural extracts to scavenge free radicals, depends on a number of parameters; the dose, structure, substituents and degree of polymerization of the molecule ${ }^{32}$.

In comparison to non-microwave treated items, high molecular weight bioactive compounds

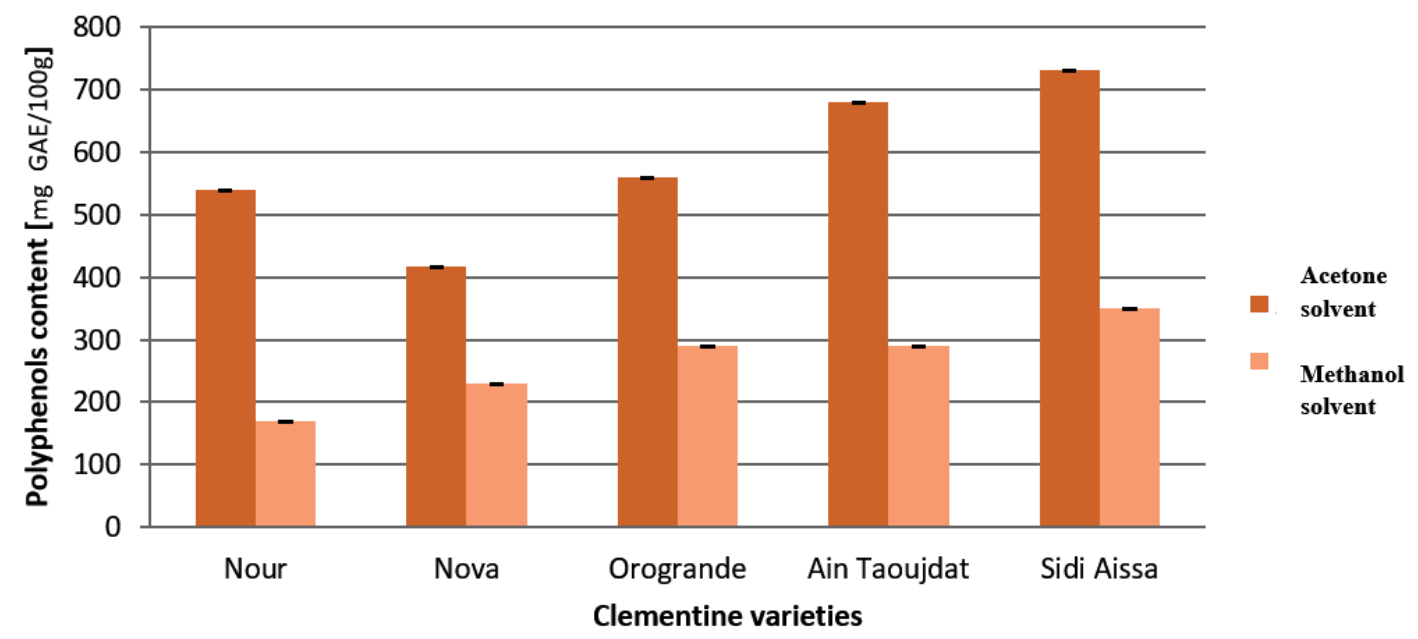

Fig. 1. Total phenol content as function of microwave assisted extraction method (methanol $80 \%$, acetone $50 \%$, $\mathrm{m} / \mathrm{v}: 5 \mathrm{~g}: 50 \mathrm{ml}, 180 \mathrm{~s}, 35^{\circ} \mathrm{C}$ and $\left.180 \mathrm{~W}\right)$. The level significance is $\mathrm{P} \leq 0.05$

Table 2. IC50 of clementine peels extracts using microwave assisted extraction (methanol $80 \%$, acetone $50 \%, \mathrm{~m} / \mathrm{v}$ : $5 \mathrm{~g}: 50 \mathrm{ml}, 180 \mathrm{~s}$, and $180 \mathrm{~W}$ )

\begin{tabular}{lccccc}
\hline Varieties Solvent & Sidi Aissa & Nova & Ain Taoujdat & Orogrande & Nour \\
\hline $\begin{array}{l}\text { Acetone } \\
(\mathrm{mg} / 100 \mathrm{~g} D M)\end{array}$ & $0.600 \pm 0.001$ & $0.800 \pm 0.002$ & $1.200 \pm 0.001$ & $1.400 \pm 0.002$ & $1.010 \pm 0.002$ \\
$\begin{array}{l}\text { Methanol } \\
(\mathrm{mg} / 100 \mathrm{~g} \mathrm{DM})\end{array}$ & $1.800 \pm 0.003$ & $1.600 \pm 0.002$ & $3.020 \pm 0.002$ & $2.800 \pm 0.001$ & $1.800 \pm 0.002$ \\
\hline
\end{tabular}




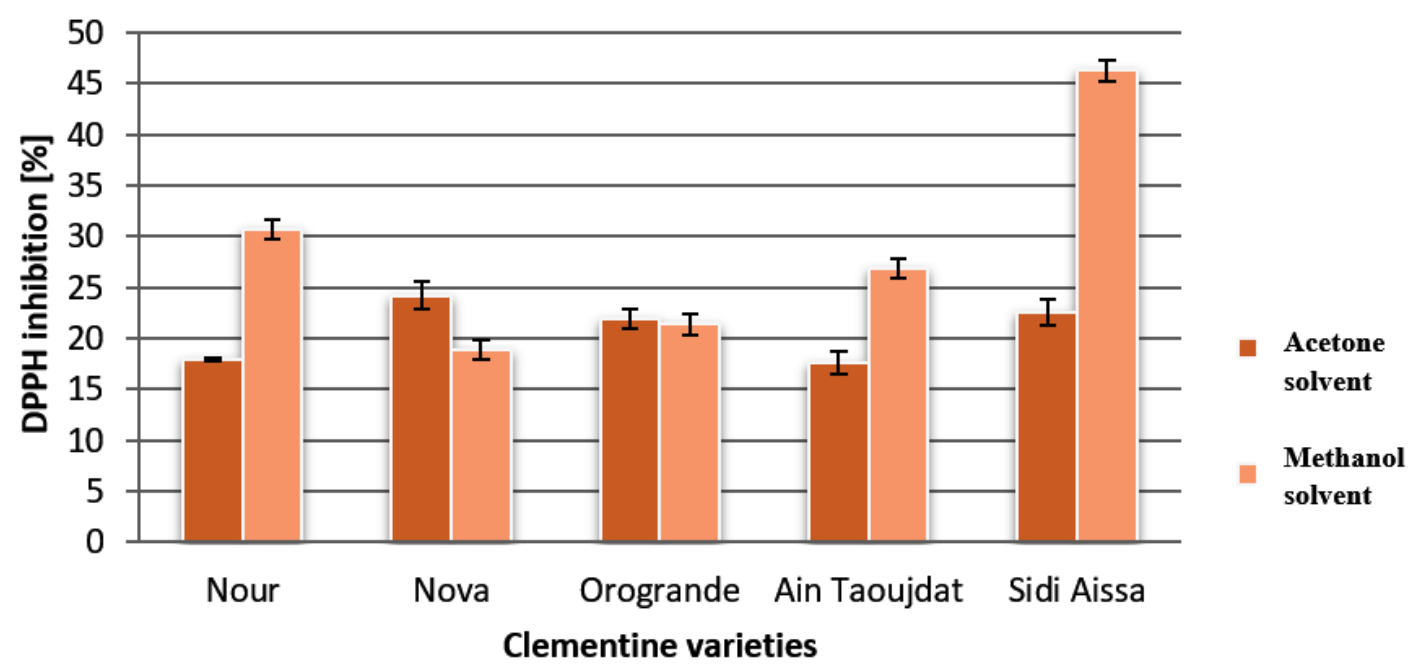

Fig. 2. Inhibition percentage $\%$ of extracts with microwave assisted extraction (methanol $80 \%$, acetone $50 \%$, m/v: $5 \mathrm{~g}: 50 \mathrm{ml}, 180 \mathrm{~s}$, and $180 \mathrm{~W}$ )

decompose into numerous small, low molecular weight molecules, enhancing phenolic content and antioxidant activity. The presence of Maillard reaction by-products accounts for the strong antioxidant activity of the extracts produced by EAM $^{33,34}$.

\section{DPPH test}

The results illustrated in Figure 2 showed the variability of the extracts for the DPPH test.

We notice in Figure 2 a variability between varieties and the two solvents acetone and methanol which values of inhibition percentage are $22.56 \%, 24.24 \%, 17.69 \%, 21.92 \%$ and $17.94 \%$ for the acetone extracts, and $46.3 \%, 18.89 \%, 26.91 \%$, $21.39 \%$ and $30.7 \%$ for the methanol extracts of (Sidi Aissa, Nova, Ain Taoujdat, Orograndé and Nour), respectively. Meanwhile, we find that the high value is recorded in the extract Sidi Aissa (46. 3\%) and the lowest value in the variety Ain Taoujdat (17.69\%) with level of signification (Pd"0.05) .This variability of these properties is due to the notable quantity of polyphenols in our extracts which plays a prominent role in the antioxidant inhibition ${ }^{35}$.

In similar study, hayat et al. (2009) ${ }^{36}$ have reported a less antioxidant activity with DPPH method (26.03\%) in citrus mandarin peel extracts obtained by microwave assisted extraction using methanol solvent. in the same study, authors reported that the extract obtained with (MAE) had higher antioxidant activity (26.03\%) than those of
Ultrasound assisted extraction (USE) (25.37\%). The lower activity of (USE) extract could be resulted from extended extraction time, hence exposure to unfavorable conditions such as light and oxygen ${ }^{37}$.

The response between the antioxidant and DPPH in the free radical scavenging process is influenced by the structural conformation of the antioxidant. When certain substances react quickly with DPPH, the number of DPPH molecules is reduced to the amount of hydroxyl groups ${ }^{38}$.

\section{CONCLUSION}

This study evaluated the potential of phenolic extraction using microwave assisted technic (MAE) with two organic solvent (Acetone, methanol) from Moroccan clementine peels. Total phenolic content and antioxidant activity of extracts of five varieties were assessed.

Results showed that the acetone solvent give the best extraction in polyphenols content compared to methanol solvent. Moreover, the extraction using acetone solvent present a high rate of total polyphenols $(730.85 \pm 0.004 \mathrm{mg} \mathrm{GAE} / 100 \mathrm{~g}$ DM) from Sidi Aissa variety compared to other varieties (Nova Ain Taoujdat, Orograndé and Nour).

The antioxidant capacity was evaluated by the determination of their scavenging power of the radical ABTS and DPPH, the more the value 
of IC50 is small the more the extract is considered as a powerful antioxidant. Therefore, we find that the high value is recorded in the extract Sidi Aissa (46. 3\%) with methanol solvent and the lowest value observed in Ain Taoujdat variety (17.69\%) using acetone solvent.

The obtained results indicate that microwave-assisted extraction using acetone solvent has shown its efficiency for phenolic compounds extraction from clementine peels.

\section{ACKNOWLEDGEMENT}

The authors would like to thank the staff of Afourer experimental station of CRRAT and the staff of "Domaine Agricole Bio" of Béni Mellal region for their support and cooperation during this study.

\section{Conflict of Interest}

\section{Funding Source}

The authors declare no conflict of interest.

This study was totally supported by the research funds of INRA Morocco.

\section{REFERENCES}

1. Mampdref. Ministère de l'agriculture, de la pêche maritime, du developpement rurale et des eaux et forêts 2020 .

2. Azzouzi, H., Elfazazi, K., Achchoub, M., Chafik, L., Jbilou, M., \& Salmaoui, S. Effect of thermal pasteurization on the physicochemical stability and nutritional quality of Moroccan Valencia late orange juice. International journal of engineering sciences \& research technology, 2018;7(8): 277-283.

3. Bampidis, V.A., Robinson, P.H., Citrus byproducts as ruminant feeds: a review. Animal Feed Science Technology, 2006;128:175-217.

4. Ledesma-Escobar, C.A., Luque de Castro, M.D., Towards a comprehensive Exploitation of citrus. Trends Food Science and Technology,2014;39:63-75.

5. Wilkins, M. R., Widmer, W., Grohmann, K., Simultaneous saccharification and Fermentation of citrus peel waste by Saccharomyces cerevisiae to produce ethanol. Biochemistry, 2007;42(12):1614-1619.

6. Pourbafrani, M., Forgacs, G., Horváth, I.S., Niklasson, C., Production of biofuels, limonene and pectin from citrus wastes. Bioresource Technology,2010;101:4246-4250.

7. Lohrasbi, M., Pourbafrani, M., Niklasson, C.,
Taherzadeh, M.J., Process design and economic analysis of a citrus waste biorefinery with biofuels and limonene as products. Bioresource Technology,2010;101:7382-7388.

8. Fernandez-Lopez, J., Fernandez-Gines, J. M., Aleson-Carbonell, L., Sendra, E., Sayas- Barber, E., Perez-Alvarez, J. A., Application of functional citrus by-products to meat products. Trends in Food Science and Techology,2004;15:176-185.

9. Marin, F.A., Soler-Rivas, C., BenaventeGarcio., Castillo, J., Perez-Alvarez, J.E., Byproducts from different citrus processes as a source of customized functional fibres. Food Chemistry,2007;100:736-741.

10. Bicu, I., Mustata, F., Cellulose extraction from orange peel using sulfite digestion reagents. Bioresource Technology,2011;102:10013-10019.

11. Wang, X., Chen, Q., \& Lu, X., Pectin extracted from apple pomace and citrus peel by subcritical water. Food Hydrocolloids, 2014;38:129-137.

12. Ramful, D., Bahorunb, T., Bourdonc, E., Tarnusc, E., Aruoma, O.I., Bioactive Phenolics and antioxidant propensity of flavedo extracts of Mauritian citrus fruits: Potential prophylactic ingredients for functional foods application. Toxicology,2010;278:75-87.

13. G. Spigno., D.M.D. Faveri. Microwave-assisted extraction of tea phenols: a phenomenological study, J. Food Eng, 2009;93:210-217

14. Hayat, K., Hussain, S., Abbas, S., Farooq, U., Ding, B., Xia, S., \& Xia, W. Optimized microwave-assisted extraction of phenolic acids from citrus mandarin peels and evaluation of antioxidant activity in vitro. Separation and Purification Technology, 2009;70(1):63-70.

15. Skenderidis, P., Leontopoulos, S., Petrotos, K., \& Giavasis, I. Optimization of vacuum MicrowaveAssisted Extraction of pomegranate fruits peels by the evaluation of extracts' phenolic content and antioxidant activity. Foods, 2020;9(11):1655.

16. Singh, A., Sabally, K., Kubow, S., Donnelly, D. J., Gariepy, Y., Orsat, V., \& Raghavan, G. S. V. Microwave-assisted extraction of phenolic antioxidants from potato peels. Molecules, 2011;16(3):2218-2232.

17. Motikar, P. D., More, P. R., \& Arya, S. S. A novel, green environment-friendly cloud point extraction of polyphenols from pomegranate peels: a comparative assessment with ultrasound and microwave-assisted extraction. Separation Science and Technology, 2021;56(6):1014-1025.

18. Casazza, A. A., Pettinato, M., \& Perego, P. Polyphenols from apple skins: A study on microwave-assisted extraction optimization and exhausted solid characterization. Separation and Purification Technology, 2020;240:116640. 
19. Bakiæ, M. T., Pedisiæ, S., Zoriæ, Z., DragoviæUzelac, V., \& Grassino, A. N. Effect of microwave-assisted extraction on polyphenols recovery from tomato peel waste. Acta Chimica Slovenica, 2019;66(2):367-377.

20. Ordoñez Torres, A., Torres León, C., Hernández Almanza, A., Flores Guía, T., Luque Contreras, D., Aguilar, C. N., \& Ascacio Valdés, J. Ultrasound microwave assisted extraction of polyphenolic compounds from Mexican "Ataulfo" mango peels: Antioxidant potential and identification by HPLC/ESI/MS. Phytochemical Analysis, 2021;32(4):495-502.

21. Simiæ, V. M., Rajkoviæ, K. M., Stojièeviæ, S. S., Velièkoviæ, D. T., Nikoliæ, N. Ė., Laziæ, M. L., \& Karabegoviæ, I. T. Optimization of microwave-assisted extraction of total polyphenolic compounds from chokeberries by response surface methodology and artificial neural network. Separation and Purification Technology, 2016;160:89-97.

22. Inoue, T., Tsubaki, S., Ogawa, B., Onishi, K., Azuma, J.I., Isolation of hesperidin from peels of thinned Citrus unshiu fruits by microwave-assisted extraction. Food Chemistry,2010;123:542-547.

23. Singleton, V.L., Orthofer, R., Lamuela-Raventos, R.M., Analysis of total phenols And other oxidation substrates and antioxidants by means of folin-ciocalteu reagent. Methods in Enzymology,1988;299:152-178.

24. Re, R., Pellegrini, N., Proteggente, A., Pannala, A., Yang, M., Rice-Evans, C., Antioxidant activity applying an improved ABTS radical cation decolorization assay. Free Radical Biology and Medicine.1999;26:1231-1237.

25. Seung-cheol, L., Seok-Moo, J., So-Young, K, Dong-Ryul, K., Seong-Chun, J., Nam, K.C., ET Ahn, D.U. Effet of Heat Treatement on the Antioxydant Activity of Extracts from Citrus Peel. Journal of Agricultural and Food Chemistry, 2004;52:3389-339.

26. Kaderides, K.; Papaoikonomou, L.; Serafim, M.; Goula, A.M. (2019). Microwave-assisted extraction of phenolics from pomegranate peels: Optimization, kinetics, and comparison with ultrasounds extraction. Chem. Eng. Process. Process Intensif. 2019;137:1-11.

27. J.P. Maran, V. Sivakumar, K. Thirugnanasambandham, R. Sridhar. Optimization of microwave assisted extraction of pectin from orange peel, Carbohydr. Polym.2013;97:703-709.

28. Mohammedi, Z. \& Atik, F. Impact of solvent extraction type on total polyphenols content and biological activity from Tamarix aphylla (L.) Karst. Inter J Pharma Bio Sci. 2011;2:609-615.

29. Trabelsi, N., Megdiche, W., Ksouri, R., Falleh, H., Oueslati, S., Bourgou, S., Hajlaoui, H. \& Abdelly, C. Solvent effects on phenolic contents and biological activities of the halophyte Limoniastrum monopetalum leaves. Food Sci Tech. 2010;43:632-639.

30. Jawad, A., Langrish, T.A.G., Optimisation of total phenolic acids extraction from mandarin peels using microwave energy: The importance of the Maillard reaction. Journal of Food Engineering,2012;109:162-174.

31. Mandal, V., Mohan, Y., Hemalatha, S. Microwave assisted extraction-An Innovative and promising extraction tool for medicinal plant research. Pharmacognosy Reviews. 2007;1:7-18.

32. Mohammedi Zohra. Etude photochimique et activités biologiques de quelques plantes médicinales de la région nord et sud-ouest de l'Algérie the thèse de doctorat en biologie université de Tlemcen faculté des sciences département de biologie moléculaire et cellulaire160, 2013.

33. Nayak, B., Berrios, J. D. J., Powers, J. R. and Tang, J. Effect of extrusion on the antioxidant capacity and color attributes of expanded extrudates prepared from purple potato and yellow pea flour mixes. Journal of Food Science, 2011;76:874-883.

34. Jawad, A., Langrish, T.A.G., Optimisation of total phenolic acids extraction frommandarin peels using microwave energy: The importance of the Maillard reaction. Journal of Food Engineering, 2012;109:162-174.

35. Kebieche, M. Activité biochimique des extraits flavonoidiques de la plante Ranunculus repens $L$ : Effet sur le diabète expérimental et l'hépatotoxicité induite par l'Epirubicine. Biochimie, These de doctorat, université mentouri Constantine, 2009;143p.

36. Hayat, K., Hussain, S., Abbas, S., Farooq, U., Ding, B., Xia, S., Xia, W. Optimized microwaveassisted extraction of phenolic acids from citrus mandarin peels and evaluation of antioxidant activity in vitro. Separation and Purification Technology, 2009;70(1):63-70. doi:10.1016/j. seppur.2009.08.012

37. S. Hemwimon, P. Pavasant, A. Shotipruk. Microwave-assisted extraction of antioxidative anthraquinones from roots of Morinda citrifolia, Sep. Purif. Technol., 2007;54:44-50.

38. Bondet, V., Williams, W.B., \& Berset, C. Kinetic and mechanism of antioxidant activity using the DPPH free radical method. Lebensmittelwissenschaft und technologie, 1997;30:609-615. 